\title{
The Application of Multiplate Resazurin Reduction Assay in The Screening for Anti-Mycobacterial Activity from Indonesian Medicinal Plants
}

\author{
Martha Sari*, Gita Syahputra and Wien Kusharyoto \\ Laboratory for Applied Genetic Engineering and Protein Design, Biotechnology Research Center, Indonesian \\ Institute of Sciences (LIPI), Indonesia, Jl. Raya Jakarta-Bogor, Km.46 Cibinong 16911
}

\begin{tabular}{l} 
Info Article \\
\hline Submitted: $26-02-2019$ \\
Revised: 04-04-2019 \\
Accepted: 30-06-2019 \\
*Corresponding author \\
Martha Sari \\
Email: \\
martha.biotek@gmail.com
\end{tabular}

\begin{abstract}
Tuberculosis (TB) is an airborne illness generated by Mycobacterium tuberculosis (Mtb), also one of the prominent infectious killers of adults worldwide. There is a pressing need to expand novel anti-mycobacterial drugs because of the increasing resistance of pathogenic mycobacteria to existing antibiotics. Native compounds acquired from microbial resources and medicinal cultivars have played an essential part as the origin of TB medications. The microplate resazurin reduction assay (MRRA) is generally utilized to assess natural and synthetic compounds for anti-mycobacterial activity. In our work, the MRRA method was employed to evaluate the antimycobacterial activity of extracts from curative plants using Mycobacterium smegmatis and Mycobacterium bovis BCG and to compare them to rifampicin as an anti-mycobacterial drug. The optimized MRRA utilized $2 \%$ aqueous DMSO and $62.5 \mu \mathrm{g} / \mathrm{mL}$ resazurin as an indicator compound in $5 \%$ aqueous Tween 80 . The optimal incubation time for M. smegmatis was 24h, and for M. bovis BCG was $48 \mathrm{~h}$. The methanolic plant extracts were acquired from various Indonesian medicinal plants known to have anti-mycobacterial activity. The various plant extracts exhibited anti-mycrobial activities confirmed by the MRRA assay. The MRRA method using M. smegmatis or M. bovis BCG as antimycobacterial targets offers a distinct advantage such as low-cost, rapid, and safe screening for anti-mycobacterial activity in a middle to high-through-putformat.
\end{abstract}

Keywords: Anti-mycobacterial, phytochemical extracts, Indonesian medicinal plants, MRRA

\section{INTRODUCTION}

Tuberculosis (TB) is a worldwide infectious disease induced by Mycobacterium tuberculosis (Dheda et al., 2014). Globally, there are estimated around 10.4 million recent cases and 13.7 million prolonged active reports accountable for 1.4 million deaths worldwide annually. Around onethird of the world's occupants are at danger to be infected by active TB and support the continuation spread of $M$. tuberculosis within communities (WHO, 2016; Maiga et al., 2012). The last few decades have also been a witness of human immunodeficiency virus/AIDS rise, an immunosuppressive ailment that enhances the virulence of the M. tuberculosis and catalyzes its transformation from inherent to active infection. Furthermore, multidrug-resistant $M$. tuberculosis (MDR-TB), known as resistance against isoniazid and rifampin, was assayed in approximately all countries investigated from 1994 to 2000 by the World Health Organization (Gupta et al., 2003), and the emersion of widely drug-resistant TB (XDR-TB) has been observed on a global scale (Migliori et al., 2003). Moreover, around 50 million people are affected by drug-resistant types of TB with approximately 500 thousand incidents of multidrug-resistant TB a year globally (WHO, 2016). Though there are ongoing new drugs being accepted for TB therapy, such as bedaquiline (Field et al., 2015; Leuwis et al., 2015) and delamanid (Szumowski et al., 2015; Leuwis et al., 2015), there are drawbacks like modest accessibility, high prices, lengthy therapy regimen, and poor conformity given by the toxicity of the drugs. The novel commercial drugs are inclined to be drained with the arising resistance (Tandolini et al., 2016) accentuating the pivotal of the ongoing search, identification, and characterization of more 
compounds for anti-TB drugs. Herb-derived systems continue to lead an essential part in healthcare, and the utilization by diverse cultures has been vastly recorded (Newman et al., 2016). It is expected that up to $80 \%$ of the world's habitants existing in the developing countries rely on herbal medicines as the primary source of healthcare, also plant products have a more indirect role in the healthcare orders of the dwelling population that mainly resides in developed countries (Lienhardt et al., 2012; Ekor 2013). Although rational and combinatorial chemistry is essential to the construction of many modern pharmaceuticals, often they serve better in refining the chemical blueprints isolated from natural product screening rather than to devise entirely new molecular backbones. The tremendous variety of plantderived compounds, therefore, make them one of the most encouraging supplies of potential new anti-tuberculosis molecules. Indonesia is famously known for its rich and uncharacterized biodiversity, and Indonesian medicinal plants are frequently used to treat diseases as a means of reducing reliance on expensive imported and/or chemical drugs. Such plants should be identified and screened on the basis of traditional knowledge for their effectiveness of the treatment of TB, and their molecular entities need to be isolated and further characterized since they might possess the high chance to become or generate new antimycobacterium substance (Garcia et al., 2012; Salomon et al., 2012). A resazurin colorimetric or fluorometric assay allows prompt drug sensitivity testing of Mycobacterium isolates with the aerobic environment, as the oxidized blue non-fluorescent dye is reduced with the presence of viable cells in the surrounding to create resorufin, which is pink in color and exhibits fluorescent. It has been notified to be an uncomplicated, specific, and dependable bioassay for the assessment of mycobacterial growth (Primm et al., 2007) and has been commonly employed for the evaluation of the anti-mycobacterial ability of both natural and synthetic compounds (O'Neill et al., 2014). By reason of its simple mechanism of testing, the rapid growth rate, and the non-pathogenic nature of $M$. smegmatis (Vissa et al., 2009), we standardized the aerobic-based resazurin reduction assay for $M$. smegmatis to establish an assay to screen for antimycobacterial activity from Indonesian medicinal plants. We also extended the assay to $M$. bovis BCG, since it shows an imminent genetic relation to $M$. tuberculosis, and its weak pathogenicity permits it to surmount the technical and regulatory problems related to handling the $M$. tuberculosis (Altaf et al., 2010). Here, we reported our investigation on the anti-mycobacterium ability of thirty-three methanolic extracts of Indonesian medicinal plants based on resazurin reduction assay and searched out potential extract concentration for optimal growth inhibition towards $M$. smegmatis and $M$. bovis BCG, subsequently.

\section{MATERIALS AND METHODS \\ Plant material and extraction}

The dried medicinal plants were enumerated with a blender, and then thoroughly extracted with methanol using Soxhlet extractor for three hours at room temperature. Thirty-three extracts from Indonesia's traditional plants were processed by adding $30 \mathrm{~g}$ of the ground compound into $300 \mathrm{~mL}$ of methanol. The concentrated extracts were collected under vacuum. The information of methanolic extracts was listed in (Table I). Afterwards, each extract was stored at $-20^{\circ} \mathrm{C}$ (O’Neill et al., 2010).

\section{Mycobacterial culture preparation.}

M. bovis strain BCG and M. smegmatis were cultivated to the logarithmic phase (OD 595 0.5) in broth medium of Middlebrook $7 \mathrm{H} 9$ consisted of $10 \%$ OADC. The cultures were kept $\left(37^{\circ} \mathrm{C}\right)$ on a shaker for 1-2 days, before being liquefied to turbidity equal with $5 \times 10^{5} \mathrm{CFU} / \mathrm{mL}$ (Taneja et al., 2007).

\section{Drug and reagent preparation.}

The plant extracts were diluted in $2 \%$ dimethyl sulfoxide (DMSO) sterile. A stock of extracts solution was filtered, sterilized $(0.22 \mu \mathrm{m})$, and stored in aliquots at $-20^{\circ} \mathrm{C}$. Resazurin sodium salt powder (Sigma Aldrich, USA) was prepared as $62.5 \mu \mathrm{g} / \mathrm{mL}$ solution in $5 \%$ Tween 80 sterile $(\mathrm{v} / \mathrm{v})$ and was filtered, sterilized, and kept at $4^{\circ} \mathrm{C}\left(\mathrm{O}^{\prime}\right.$ Neill et al., 2010).

\section{Screening anti-mycobacterial extract with MRRA}

The MRRA was performed using clear 96 wells microplate. The stock solution of rifampicin $(20 \mu \mathrm{g} / \mathrm{L})$ as a positive control and plant extracts (10mg/mL) were prepared in DMSO, aliquoted, and stored at $-20^{\circ} \mathrm{C}$. The composition of negative control wells (DMSO solutions) was $100 \mu \mathrm{L}$ of Middlebrook7H9 medium without antibiotic. Each of the wells was supplemented with $2 \mathrm{~mL}$ of $10 \%$ OADC, and approximately $5 \times 10^{4}$ cell for $M$. smegmatis and $M$. bovis was added in $50 \mu \mathrm{L}$ (OD 
$595 \sim 0.001)$. After that, $25 \mu \mathrm{L}$ of resazurin was added and observed at $37^{\circ} \mathrm{C}$ after $24 \mathrm{~h}$ for a color change from blue to pink. The fluorescence of the MRRA plate was measured by excitation wavelength at $530 \mathrm{~nm}$ and emission wavelength at 590nm using Varioscan (fluorometric reader). The percentage of the inhibition of viability was defined (1) (O’Neill et al., 2010).

Growth inhibition $(\%)=\left(1-\frac{\mathrm{A}}{\mathrm{B}}\right) \times 100 \%$

$A=$ test or positive control well fluorescence; $\mathrm{B}=$ negative control well fluorescence.

Determination of optimal extract concentration The optimal extract concentrations for growth inhibition towards $M$. smegmatis and $M$. bovis BCG were determined by the MRRA methods using a series of extract concentrations $(0.3 \mathrm{mg} / \mathrm{mL}$, $0.2 \mathrm{mg} / \mathrm{mL}, 0.1 \mathrm{mg} / \mathrm{mL}$, and $0.05 \mathrm{mg} / \mathrm{mL}$ ), each of which was incubated with $M$. bovis BCG for $48 \mathrm{~h}$ and $M$. smegmatis for $24 \mathrm{~h}$, respectively. After that, resazurin was added to all the wells, and incubation was continued for $24 \mathrm{~h}$. Afterwards, mycobacterial growth was assessed fluorometrically as described above (O'Neill et al., 2010).

\section{RESULTS AND DISCUSSION}

Screening of anti-mycobacterial activity using MRRA.

In our effort to evaluate the antimycobacterial activity from Indonesian medicinal plants, we relied on the established MRRA protocol previously described using $M$. tuberculosis $\mathrm{H} 37 \mathrm{Rv}$ as an antimycobacterial target (O'Neill et al., 2014). However, since M. smegmatis and $M$. bovis BCG were used as surrogate models in our experiments, the protocol had to be modified slightly to accommodate different growth characteristics of both strains compared to $M$. tuberculosis. It has been declared that one day for incubation of $M$. smegmatis was sufficient to evaluate the antimycobacterial activity of compounds from the Library of Pharmacologically Active Compounds (LOPAC) (Abidi et al., 2014). Another report indicated that $48 \mathrm{~h}$ of drug exposure towards $M$. bovis BCG was necessary to determine growth inhibition under aerobic conditions (Murugasu-Oei et al., 2000). Our preliminary experiments revealed that one day of incubation for $M$. smegmatis and two days of incubation for $M$. bovis BCG were sufficient to detect antimycobacterial activity using rifampicin as an antibiotic (data not showed), which corresponded to the reports mentioned above. Following resazurin addition, the wells were observed after $24 \mathrm{~h}$ for a color change from blue to pink, and mycobacterial growth was evaluated fluorometrically as previously explained (Taneja et al., 2007). Similarly, we included the Tween 80 as a surfactant, for the bioassay reagents in order to reduce the activity of the Mycobacterium cells to stick to each other (Schafer et al., 1999). The increase in the available surface space of Mycobacterium cells allowed greater contact and better absorption and metabolism of the resazurin solution, thereby facilitating its reduction to resorufin (Twigg et al., 1945). The action mode of MRRA to the plant extracts tested for anti- $M$. smegmatis and M. bovis activity have been observed using resazurin as color indicators. The MRRA assay based on the oxidation of resazurin dye reduction was evaluated, and the qualitative data were observed from color change blue to pink (Figure 1). In this research, we used MRRA verification to determine antimycobacterial activity based on extract intensity compared to rifampicin intensity as a positive control. The color change has happened because resazurin has been reduced to become resorufin by Mycobacterium cells (Webster et al., 2010). Red color indicates a negative anti-mycobacterium activity, whereas blue color implies a potential anti-mycobacterium. From 33 medicinal plant extracts, only 5-6 extracts showed potential antimycobacterial activity. Six methanol extracts for anti-M. smegmatis $(A, 3,4) C$. sappan, $(\mathrm{B} 3,4)$ P. granatum, $(\mathrm{C} 3,4)$ Z. americans, C $(9,10)$ Z. aromaticum, (E 11, 12) D. triquetrum, (F 5, 6) B. frustescens, and almost all extract as anti $M$. smegmatis depicted as anti $M$. bovis activity exception B. frustescens. Similarly, Banfi et al. (2013) found that the same result in color change from blue to pink was identified on mycobacterium after $72 \mathrm{~h}$ of observation.

The modified MRRA protocol was employed to screen for the antimycobacterial activity of thirty-three methanolic plant extracts from various Indonesian medicinal plants. The species of selected plants and the used parts of the plants are listed in (Table I). The choice of the plants was based on word of mouth information or their ethnobotanical uses, either well documented or not, which may correspond to similar use in Indian's Ayurveda or Traditional Chinese Medicine. The selected extracts showed to have different inhibition intensity indicating that all extracts tested produce assayable anti-mycobacterial activity (Table I). 

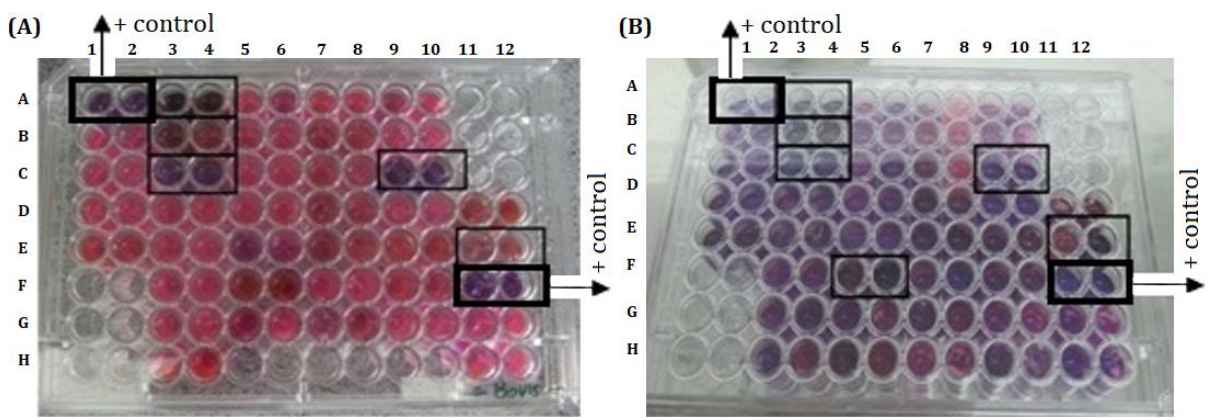

Figure 1. Results of screening in MRRA assay. The rectangles in (a) show potential plant extracts for anti- $M$. smegmatis (A 3, 4) C. sappan, (B 3, 4) P.granatum, (C 3, 4) Z. amaricans, C $(9,10)$ Z. aromaticum, (E 11, 12) D. triquetrum, $(\mathrm{F} 5,6)$ B. frustescens. The rectangles in (b) show the potential plant extracts for anti-M.bovis $(\mathrm{A} 3,4)$ C. sappan, (B 3, 4) P. granatum, (C 3, 4) Z. amaricans, C $(9,10)$ Z. aromaticum, $(\mathrm{E} 11,12)$ D. triquetrum.

Table I. List of the selected plants and the used parts as anti-mycobacterium candidates

\begin{tabular}{|c|c|c|c|c|}
\hline $\begin{array}{l}\text { Scientific and Vernacular } \\
\text { Name }\end{array}$ & Parts used & Traditional Use & M. smegmatis & M. bovis BCG \\
\hline Alstonia scholaris & bark & anti-bacterial, fever & - & - \\
\hline Azadirachta indica & leaves & antibacterial, fever & - & - \\
\hline Arcangelica flava & bark & fever & - & - \\
\hline Brucea javanica & fruit & fever, anti-bacterial & + & + \\
\hline Baeckea frustescens & whole plant & leukemia, anti-bacterial & ++++ & + \\
\hline Caesalpinia sappan & bark & anti-bacteria, antioxidan & ++++ & ++++ \\
\hline Centella asiatica & whole plant & antihistamine & - & - \\
\hline Clerodendron serratum & leaves & cough, "gurah" & - & - \\
\hline Cymbopogon citratus & leaves & cough, anti-catarrhal & + & + \\
\hline Desmodium triquetrum) & leaves & cough, anti-malaria & +++ & +++ \\
\hline Drymoglossum piloselloides & whole plant & anti-inflammatory & - & - \\
\hline Eleutherina americana & bulb & respiration & - & - \\
\hline Erythrina lithosperma & leaves & cough & + & ++ \\
\hline Euphorbia hirta & leaves & cough & + & ++ \\
\hline Gynura procumbeus & leaves & cough, anti-inflammatory & + & + \\
\hline Hedyotis corymbosa & whole plant & fever & + & - \\
\hline Leucas lavanduvolia & fruit & cough, fever & + & + \\
\hline Morus alba & leaves & throat inflammation & + & + \\
\hline Merreimia mammosa & tuber & cough, lung infection & - & - \\
\hline Peperomia pellucida & whole plant & cough, fever & + & + \\
\hline Plucea indica & leaves & cough, fever & - & - \\
\hline Plantago major & stem leaves & astringent, anti-bacterial & + & + \\
\hline Punica granatum & rind of fruit & astringent & ++++ & +++ \\
\hline Petiveria alliacea & leaves & anti-inflammation & - & - \\
\hline Sida rhombifolia & Whole plant & influenza & - & - \\
\hline Solidago virgaurea & leaves & anti-catarrhal & + & + \\
\hline Tinospora cordifolia & bark & hepatoprotector & - & - \\
\hline Usnea barbata & whole plant & anti-bacteria, anti-fungi & - & - \\
\hline Zingiber amaricans & rhizomes & cough, asthma & ++++ & ++++ \\
\hline Zingiber aromaticum & rhizomes & cough, asthma & ++++ & ++++ \\
\hline Zingiber zerumbet & rhizomes & cough, asthma & - & - \\
\hline Ziziphus mauritiana & leaves & asthma, fever & + & + \\
\hline
\end{tabular}

${ }^{++++}$Strong inhibition, ${ }^{+++}$Medium, ${ }^{++}$Low, ${ }^{+}$Very low, - No activity 


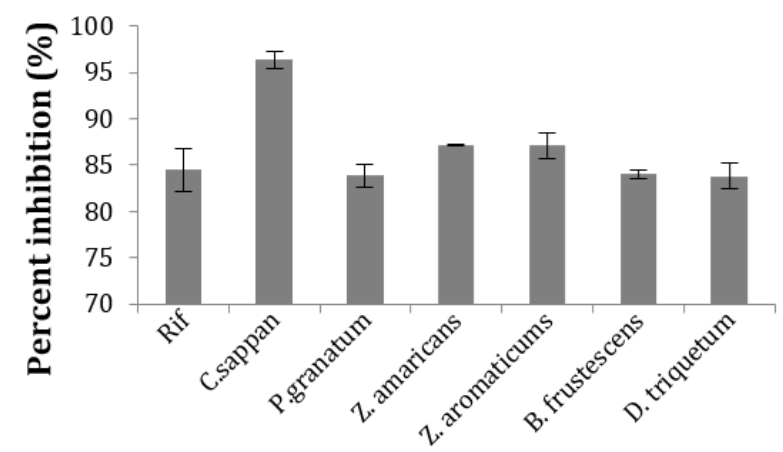

(a) Extracts

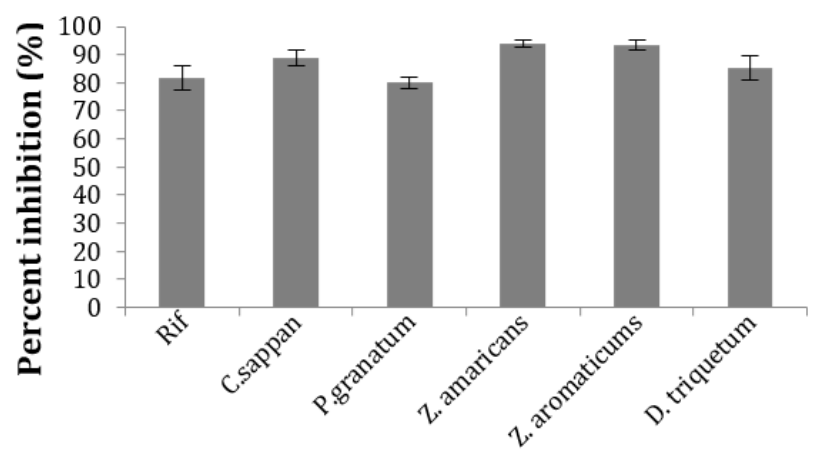

(b) Extract

Figure 2 Antimycobacterial activity of potential plant extracts tested against (a) Mycobacterium smegmatis (b) Mycobacterium bovis. Rif: Rifampicin. Activity was assessed using the MRRA after 24 hours of treatment with the $30 \mathrm{mg} / \mathrm{ml}$ extracts in $2 \%$ aqueous DMSO.

Based on the sharpness of colors characteristics obtained by using a fluorometric reader, the inhibition of plant extracts was scored by $(++++$, ,,++++++ and - ) respectively. The plant extracts with the highest activity were from $C$. sappan, $P$. granatum, $Z$. amaricans, $Z$. aromaticum, $D$. triquetrum, and $B$. frustescens. Some of the plants have been known as a treatment for specific diseases, and in general, these plants are used by local people empirically or as standardized plant extracts, which include $P$. indica, $Z$. aromaticum, and Z. zerumbet (Rianto, 2007; Singh et al., 2014; Abdul et al., 2008; Bhowmik et al., 2013). In addition, potential plant with the protective compound in the body such as antioxidant, antiproliferative, inhibitor for rheumatoid arthritis and hepatoprotector have been investigated in C. sappan, $P$. granatum and $D$. triquetrum extracts (Liang et al., 2013; Kadir et al., 2014; Lucci et al., 2015; Wu et al., 2014; Ishola et al., 2015). According to the studies conducted by Webster et al. (2010), anti-mycobacterial activity towards M. tuberculosis H37Ra, and M. avium can be found in traditional medicinal plants. Moreover, Heracleum maximum, one of the traditional plants in Canada when extracted in methanol, had inhibitory activity towards M. tuberculosis H37 (O’Neill et al., 2007), while another traditional Canadian plant J. communis also exhibited anti-mycobacterial activity (Carpenter et al., 2012). Further confirmation was performed in order to calculate the potency of extracts in growth the inhibition of $M$. smegmatis and $M$. bovis by microplate fluorometric scan with excitation at $530 \mathrm{~nm}$ and emission at $590 \mathrm{~nm}$.

\section{Selected potential plant extract to fight against M. smegmatis and M. bovis}

In order to confirm the formation of antimycobacterial activity from the selected potential plant extracts, the crude extracts of each plant extracted on methanol solution were quantified on a fluorometric reader with 590nm emission and $530 \mathrm{~nm}$ excitation wavelength. The MRRA assay was used as guide screening for mycobacterium activity. In this study, M. smegmatis and $M$. bovis were applied as microbial models on MRRA screening before using $M$. tuberculosis for advance research. The results indicated that the antimycobacterial activity of selected plant extract showed a different pattern when tested on $M$. smegmatis or M. bovis BCG (Figure 2). Generally, all of the plant extracts have the activity against $M$. smegmatis even though with a lower value than $C$. sappan. The range of percent inhibition in $M$. smegmatis activity was $83.85 \%-96.32 \%$. The $C$. sappan extract exhibited more than $95 \%$ inhibition against $M$. smegmatis, compared with rifampicin (85\%) observed 24h (Figure 2a).

In the same way, C. sappan, Z. amaricans, and $Z$. aromaticum have the potency to inhibit another microbial test, i.e., M. bovis (Figure 2b). They have the highest percentage, around $90 \%$ compared with $P$. granatum and D. triquetrum $(80 \%$ approximately). An antimycobacterial assay used dormant and actively $M$. smegmatis and $M$. bovis BCG in the study to test the resazurin reduction tests for screening of an anti-tubercular compound (O'Neill et al., 2010). MRRA is a simple, effective, and efficient assay for performing tests on Mycobacterium bacteria such as M. tuberculosis, 


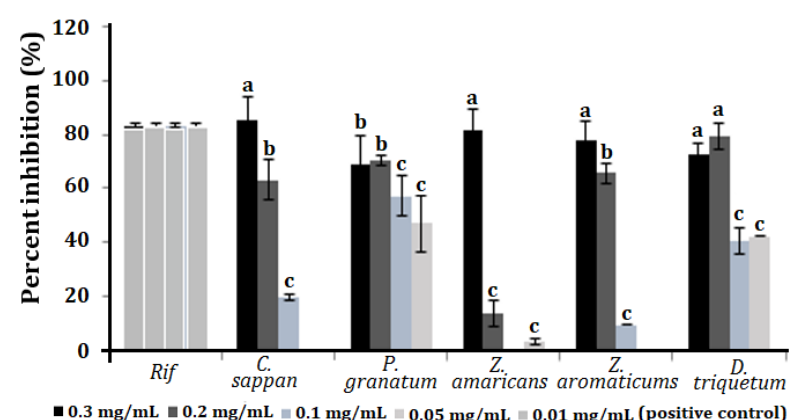

(a)

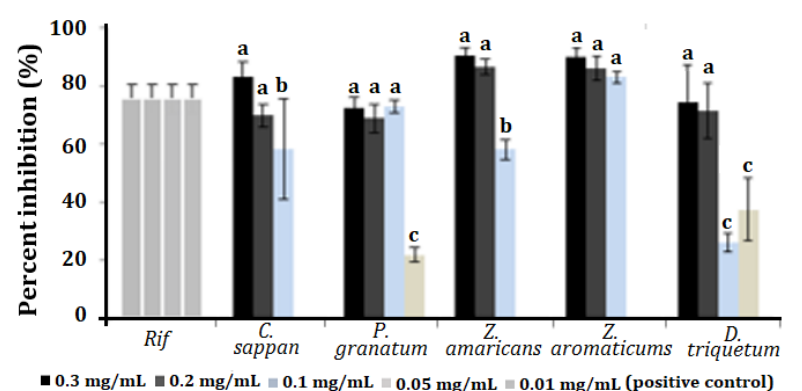

(b)

Figure 3. Evaluation of the effect of various extract concentration in inhibiting the growth of a) $M$. smegmatis and b) M. bovis BCG using MRRA assay after incubation for $24 \mathrm{~h}$. The concentration of rifampicin as positive control was $0.01 \mathrm{mg} / \mathrm{mL}$. Different letters on each bar indicated significant differences (LSD; $\mathrm{P}<0.01)$.

M. avium, M. bovis BCG, and M. smegmatis, as evidenced by the research conducted by Martin et al. (2003) and Sivakumar and Jayaraman (2011). On the other hand, Sivakumar and Jayaraman (2011) reported that Zingiber has poor activity against Mycobacterium in his study with Alamar Blue Assay. There was antimycobacterial activity in several medicinal plants that are utilized as selfmedication by sufferers with AIDS in Thailand, and 12 plants including $Z$. zerumbet were tested against M. tuberculosis employing the Microplate Alamar Blue Assay (Phongpaichit et al., 2006).

\section{Optimization of potential plant extracts.}

The optimization has been done to determine the best extract concentration to fight against $M$. bovis and $M$. smegmatis (Figure 3). The results show that the concentration of $0.3 \mathrm{mg} / \mathrm{mL}$ plant extracts is the optimal concentration to fight against the growth of $M$. smegmatis with extracts from C. sappan, Z. amaricans, Z. aromaticum and $D$. triquetum (Figure 3a). However, P. granatum extracts were optimal to fight against $M$. smegmatis on a concentration of $0.2 \mathrm{mg} / \mathrm{mL}$. Based on our results for almost all plant extracts evaluated, a plant extract concentration of $0.3 \mathrm{mg} / \mathrm{mL}$ was sufficient to inhibit the growth of $M$. smegmatis with comparable inhibition activity as rifampicin. The use of concentration of plant extracts of $0.2 \mathrm{mg} / \mathrm{mL}$ and a lower concentration below its could sufficient be potential to inhibit $M$. smegmatis although its generally not as strong as rifampicin. While at lowest concentrations it had a weak activity.

The inhibition of $M$. bovis growth against all plant extract concentrations $(0.2-0.3 \mathrm{mg} / \mathrm{mL})$ evaluated, has an average activity comparable to rifampicin. Beside of the case of extracts obtained from $P$. granatum and $Z$. aromaticums with a lower concentration of $0.1 \mathrm{mg} / \mathrm{mL}$ could be sufficient to exhibit a comparable inhibition activity as rifampicin. In the case of the use of plant extracts with the higher concentration $(0.3 \mathrm{mg} / \mathrm{mL})$ for all of extract against $M$. bovis could might not be necessary, because higher plant extract concentrations exhibited similar growth inhibition as extract concentration of $0.2 \mathrm{mg} / \mathrm{mL}$, but the effect could increase a possible higher risk of toxicity. To this end, the percent of inhibition on medicinal plant extracts based on MRRA assay influenced by the extract concentration and mycobacterial used.

Based on the research conducted by Razmavar et al. (2014) concerning the activity of antibacterial compounds in $B$. frustescens, the chemical composites like alkaloids, flavonoids, steroids, terpenoids, phenols, and carbohydrates were found in this species. It is similar to Srinivasan et al. (2012) as they studied the phytochemical compound in C. sappan, and it contains steroids, tannins, saponins, phenols, and flavonoids. According to another study, flavonoids (flavonol or 3-hydroxy flavone) exhibited a potency of 38\% inhibition. The flavonols which are moderately active against $M$. tuberculosis are flavonols, flavones, flavanones, and chalcones (Coelho et al. 2010). MRRA screen was done because it can be simple, low cost, and safely used for performing tests on Mycobacterium, such as M. tuberculosis, M. avium, M. bovis BCG, and M. smegmatis according to research conducted by Martin et al. (2003). The MRRA method was done to screen the extracts of 
natural materials towards inhibition of tested cells as an anti-mycobacterial activity. Further studies are required to establish the reproducibility of the MRRA and to further identify the active compounds in the extracts responsible for their antimycobacterial activity.

\section{CONCLUSIONS}

The various plant extracts acquired from some Indonesian medicinal plants have been confirmed to exhibit an anti-mycobacterial activity using The Microplate Resazurine Reduction Assay (MRRA). The study recommends that all extract concentration of $0.3 \mathrm{mg} / \mathrm{mL}$ is an optimal concentration to inhibit the growth of $M$. smegmatis and $M$. bovis with comparable inhibition activity as rifampicin (as anti-mycobacterial drugs).

\section{ACKNOWLEDGMENTS}

The authors would like to thank Eka Arismayanti and Rizqi for their assistance with the plant material, extraction, screening, identification, and DSMZ culture collection for the permission to use M. smegmatis and M. bovis. This work was financially supported by a grant from the competitive research program of the Indonesia Institute of Sciences (LIPI).

\section{REFERENCES}

Abdul ABH., Al ZAS., Tailan ND., Wahab SIA., Zain ZNM., Ruslay S., and Syam MM., 2008. Anticancer activity of natural compound (Zerumbone) extracted from Zingiber zerumbet in human Hela cervical cancer cells. Int J Pharmacol. 4(3): 160-168. DOI: 10.3923/ijp.2008.160.168.

Abidi., Syed H., Ahmed K., Sherwani., Sikander K., Bibi., Nazia-Kazmi., Shahana U., 2014. Detection of Mycobacterium smegmatis biofilm and its control by natural agents. Int J Curr Microbiol Appl Sci. 3(4): 801-812.

Altaf M., Miller CH., Bellow DS., and O'Toole R., 2010. Evaluation of the Mycobacterium smegmatis and BCG models for the discovery of Mycobacterium tuberculosis inhibitors. Tuberculosis (Edinb), 90(6): 333-7. DOI: 10.1016/j.tube.2010.09.002.

Banfi E., Scialino G., and Monti-Bradgadin C., 2013. Development of microdilution method to evaluate Mycobacterium tuberculosis drug susceptibility. J Antimicrob Chemother. 52: 796-800. DOI: $10.1093 / \mathrm{jac} / \mathrm{dkg} 439$.

Bhowmik, Debjit, Gopinath., Harish., Kumar B., Pragati., Duraivel SG., Aravind-Kumar KP., and Sampath., 2013. Medicinal uses of Punica granatum and its health benefits. $J$ Pharmacogn Phytochem. 1 (5): 81-92.

Carpenter CD., O’Neill T., Picot N., Johnson JA., Robichaud GA., Webster D-Gray., Christopher A., 2012. Anti-mycobacterial natural products from the Canadian medicinal plant Jupenirus communis. J Ethnopharmacol. 143: 695-700. DOI: 10.1016/j.jep.2012.07.035.

Coelho RG., Honda NK., Vieira MC., Brum RL., Pavan FR., Leite CQ., Fujimura-Cardoso., Claudia AL., 2010. Chemical composition and antioxidant and antimycobacterial activities of Bromelia balance (Bromeliaceae). J Med Food. 13(5): 1277-1280. DOI: 10.1089/jmf.2009.0032.

Dheda K., Gumbo T., Gandhi NR., Murray M., Theron G., Udwadia Z., Migliori GB., Warren R., 2014. Global control of tuberculosis: from extensively drug-resistant to untreatable tuberculosis. Lancet Respir Med. 2(4): 32138. DOI: 10.1016/S2213-2600(14)70031-1.

Ekor M., 2013. The growing use of herbal medicines: issues relating to adverse reactions and challenges in monitoring safety. Front Pharmacol. 4: 177. DOI: 10.3389/fphar.2013.00177.

Field SK., 2015. Bedaquiline for the treatment of multidrug-resistant tuberculosis: great promise or disappointment?. The $A d v$ Chronic Dis. 6(4): 170-184. DOI: 10.1177/2040622315582325.

García V., Palma JP., Nicolás and Rivera G., 2012. Recent advances in antitubercular natural products. Eur J Med Chem. 49: 1-23. DOI: 10.1016/j.ejmech.2011.12.029.

Gupta V., Gupta A., Arora S., Bambery P., Dogra MR and Agarwal A., 2003. Presumed tubercular serpiginous-like choroiditis: clinical presentations and management. Ophthalmology. 110(9): 1744-9. DOI: 10.1016/S0161-6420(03)00619-5.

Ishola IO., Akinyede AA., Robert AK., Omilabu SA., 2015. Hepatoprotective and antioxidant activities of Hepacare, a herbal formulation against carbon tetrachloride-induced liver injury. Drug research. 65: 30-39. DOI: 10.1055/s-0034-1371829.

Kadir FA., Kassim NM., Abdulla MA., Kamalidehghan B., Ahmadipour F. and Yehye, WA., 2014. PASS-predicted hepatoprotective activity of Caesalpinia sappan in thioacetamide-induced liver 
fibrosis in rats. Journal of Scientific World. 2014:301879. DOI: 10.1155/2014/301879.

Lewis JM. and Sloan DJ., 2015. The role of delamanid in the treatment of drug-resistant tuberculosis. Ther Clin Risk Manag, 11: 779791. DOI: $10.2147 / T C R M . S 71076$.

Lewis JM., Hine P., Walker J., Khoo SH., Taegtmeyer M., Squire SB. and Sloan DJ., 2016. First experience of effectiveness and safety of bedaquiline for 18 months within an optimized regimen for XDR-TB. Eur Respir J. 47(5): 1581-1584. DOI: 10.1183/13993003.01980-2015.

Liang CH., 2013. Brazilein from Caesalpinia sappan L. antioxidant inhibits adipocyte differentiation and induces apoptosis through caspase- 3 activity and anthelmintic activities against Hymenolepis nana and Anisakis simplex. Evid Based Complement Alternat Med. 864892: 1-14. DOI: 10.1155/2013/864892.

Lienhardt C., Raviglione M., Spigelman M., Hafner R., Jaramillo E., Hoelscher M., Zumla A and Gheuens J., 2012. New drugs for the treatment of tuberculosis: Needs, challenges, promise, and prospect for the future. J Infect Dis. 205: 241-249. DOI: 10.1093/infdis/jis034.

Lucci P., Pacetti D., Loizzo MR. and Frega NG., 2015. Punica granatum cv. Dente di Cavallo seed ethanolic extract: antioxidant and antiproliferative activities. Food Chem. 16: 475-483. DOI: 10.1016/j.foodchem.2014.06.123.

Maiga M., Lun S., Guo H., Winglee K., Ammerman NC. and Bishai WR., 2012. Risk of tuberculosis reactivation with tofacitinib (CP-690550). J Infect Dis. 205(11): pp. 1705-1708. DOI: 10.1093/infdis/jis269.

Martin S., Camachi M., Portaels F., and Palomino J., 2003. Resazurin microtiter assay plate testing of Mycobacterium tuberculosis susceptibilities to second-line drugs: rapid, simple, and inexpensive method. Antimicrob Agents Chemother. 47(11): 3616-3619. DOI: 10.1128/AAC.47.11.3616-3619.2003.

Migliori GB., Centis R., D'Ambrosio L., Spanevello A., Borroni E., Cirillo DM. and Sotgiu G., 2013. Totally drug-resistant and extremely drugresistant tuberculosis: the same disease? Clint Infect Dis. 54: 1379-1380. DOI: 10.1093/cid/cis128.

Murugasu OB., and Dick T., 2000. Bactericidal activity of nitrofurans against growing and dormant Mycobacterium bovis BCG. J Antimicrob Chemother. 46: 917-919. PMID: 11102410.

Newman DJ. and Cragg GM., 2016. Natural Products as Sources of New Drugs from 1981 to 2014. J Nat Prod. 79(3): 629-61. DOI: 10.1021/acs.jnatprod.5b01055.

O’Neill TE., Johnson JA., Webster D., Gray CA., 2010. The Canadian medicinal plant Heracleum maximum contains antimycobacterial diynes and furanocoumarins.

Ethnopharmacol.147: 232-237. DOI: 10.1016/j.jep.2013.03.009.

O'Neill TE., Li H., Colquhoun CD., Johnson JA., Webster D. and Gray CA., 2014. Optimization of the microplate resazurin assay for screening and bioassay-guided fractionation of phytochemical extracts against Mycobacterium tuberculosis. Phytochem Anal. 10: 1002. DOI: 10.1002/pca.2516.

Phongpaichit S., Vuddhakul V., Subhadhirasakul S. and Wattanapiromsakul C., 2006. Evaluation of the antimycobacterial activity of extracts from plants used as self-medication by AIDS patients in Thailand. Pharm Biol. 44(1): 7175.

https://doi.org/10.1080/13880200500531 060.

Primm TP. and Franzblau SG., 2007. Recent advances in methodologies for the discovery of antimycobacterial drugs. Curr Bioact Compd. 3: 201-208. DOI: 10.2174/157340707781695550.

Razmavar S., Abdulla MA., Ismail SB. and Hassandarvish P., 2014. Antibacterial activity of leaf extracts of Baeckea frustescens against Methicillin-resistant Staphylococcus aureus. BioMed Res Int. 2014: 521287. http://dx.doi.org/10.1155/2014/521287.

Rianto S., 2007. Identification of the isolated compounds from Zingiber amaricans BL. Rhizome. Indo J Chem. 7(1): 93-96. https://doi.org/10.22146/ijc.21720.

Salomon CE. and Schmidt LE., 2012. Natural products as leads for tuberculosis drug development. Curr Top Med Chem. 12(7): 735-65. PMID: 22283816.

Schafer MP., Fernback JE. and Ernst MK., 1999. Detection and characterization of airborne Mycobacterium tuberculosis H37Ra particles, a surrogate for airborne pathogenic $M$. tuberculosis. Aerosol Sci Technol. 30: 161173. 
https://doi.org/10.1080/02786829930475 0.

Singh CB., Chanu SB., K Lenin., Swapana N., Cantrell C., and Ross S A., 2014. Chemical composition and biological activity of the essential oil of rhizome of Zingiber zerumbet (L) Smith. J Pharmacogn Phytochem. 3(3): 130-133.

https://pubag.nal.usda.gov/catalog/62328.

Sivakumar A., and Jayaraman G., 2011. Antituberculosis activity of commonly used medicinal plants of South India. J Med Plants Res. $\quad$ 5(31): 6881-6884. https://doi.org/10.5897/JMPR11.1397.

Srinivasan R., Selvam G., Ganapathy K., Sakthivel M., Krishnamurthy BR., Karthikeyan M., Gopi M., and Govindasamy C., 2012. In vitro antimicrobial activity of Caesalpinia sappan L. Asian Pac J Trop Biomed. 2(1): S136-S139. https://doi.org/10.1016/S22211691(12)60144-0.

Szumowski L., 2015. Profile of delamanid for the treatment of multidrug-resistant tuberculosis. Drug Des Dev Ther. 9: 677-682. DOI: $10.2147 / D D D T . S 60923$.

Tadolini M., Garcia-Prats., Anthony JD., Lia H., Catherine C., Rosella SH., Simon MBJ., Ferreira H., Caminero JA., Jonckheere S., Sinha A., Herboczek K., Khaidarkhanova Z., Hayrapetyan A., Khachatryan N., Urtkmelidze LC., Esposito S., Matteelli A., Furin JV., Francis-Migliori, Giovanni B., 2016. Compassionate use of new drugs in children and adolescents with multidrug-resistant and extensively drug-resistant tuberculosis: early experiences and challenges. Eur Respir J. 48(3): 938-943. DOI: 10.1183/13993003.00705-2016.

Taneja NK., and Tyagi JS., 2007. Resazurin reduction assays for screening of antitubercular compounds against dormant and actively growing Mycobacterium bovis BCG and Mycobacterium smegmatis. J Antimicrob Chemother. 10: $1093 . \quad$ DOI: $10.1093 / \mathrm{jac} / \mathrm{dkm} 207$.

Twigg RS., 1945. Oxidation-reduction aspects of resazurin. Nature. 155: 401-402. https://doi.org/10.1038/155401a0.

Vissa VD., Sakamuri RM., Li W., and Brennan PJ., 2009. Defining mycobacteria: shared and specific genome features for different lifestyles. Indian J Microbiol. 49: 11-47. DOI: 10.1007/s12088-009-0006-0.

Webster DG., Le TD., More J., Manning T., Kunimoto D., LeBlanca D., Jhonson JA., Gray CA., 2010. Antimycobacterial screening of traditional medicinal plants using the microplate resazurin assay. Can J Microbiol. 56: 487494. DOI: $10.1139 / \mathrm{w} 10-035$.

WHO., 2016. Library Cataloguing-in-Publication Data Global tuberculosis report 2016. World Health Organization. WHO/HTM/TB/.

Wu J., Ma G., Li H., Wu C., Tan Y., Zhang T., Chen F., Guo P., and Zhang X., 2014. Chemical constituents with antihyperlipidemic activities from Desmodium triquetrum. Chinese Herbal Medicines. 6: 324-327. https://doi.org/10.1016/S16746384(14)60049-6. 